\title{
Green turtle population structure in the Pacific: new insights from single nucleotide polymorphisms and microsatellites
}

\author{
Suzanne E. Roden ${ }^{1, *}$, Phillip A. Morin ${ }^{1}$, Amy Frey ${ }^{1}$, George H. Balazs ${ }^{2}$, \\ Patricia Zarate ${ }^{3}$, I-Jiunn Cheng ${ }^{4}$, Peter H. Dutton ${ }^{1}$
}

\begin{abstract}
${ }^{1}$ Marine Mammal and Turtle Division, Southwest Fisheries Science Center, National Marine Fisheries Service, National Oceanic and Atmospheric Administration, 8901 La Jolla Shores Drive, La Jolla, California 92037, USA ${ }^{2}$ Marine Turtle Research Program, Pacific Islands Fisheries Science Center, National Marine Fisheries Service, National Oceanic and Atmospheric Administration, 2570 Dole Street, Honolulu, Hawaii 96822, USA

${ }^{3}$ Marine Science Program, Charles Darwin Foundation, Santa Cruz Island, Galapagos Islands, Ecuador ${ }^{4}$ Institute of Marine Biology, National Taiwan Ocean University, 2 Pei-Ning Road, Keelung 20224, Taiwan, ROC
\end{abstract}

\begin{abstract}
A set of nuclear single nucleotide polymorphisms (SNPs) and microsatellite markers was used to detect genetic stock structure among 5 Pacific green turtle Chelonia mydas nesting populations. We sampled populations in the Galapagos Islands, Ecuador ( $\mathrm{n}=57$ ), Colola, Mexico $(n=75)$, French Frigate Shoals, Hawaii $(n=141)$, Yap, Micronesia $(n=73)$, and Wan-an, Taiwan $(n=57)$, to represent eastern, central, and western Pacific regions. A combination of 29 single independent SNPs and linked SNPs combined as haplotypes were used for a total of 20 independent markers. In addition, 8 polymorphic microsatellite markers were applied to the same sample set. Both sets of nuclear markers confirmed significant differentiation between all sampled populations in the 3 Pacific regions ( $\mathrm{p} \leq 0.001$ ). The use of these SNPs and microsatellites resulted in sufficient power to detect small population differences not seen in previous studies using smaller numbers of nuclear markers. Our results suggest that male-mediated gene flow between regional nesting stocks is more limited than previously believed, allowing the potential to delineate stocks more clearly. Finally, we discuss the value of SNP markers as an alternative or complement to other nuclear markers such as microsatellites for the examination of stock structure.
\end{abstract}

KEY WORDS: Green turtle · Chelonia mydas · Single nucleotide polymorphism • SNP • Microsatellite $\cdot$ Sea turtle $\cdot$ Genetics $\cdot$ Conservation

\section{INTRODUCTION}

The use of genetic information may aid in understanding the population structure and reproductive behavior of highly migratory species. Forces affecting dispersal, either extrinsic, such as environmental influences, or intrinsic, such as innate behavior, may have substantial effects on the genetic structure of populations (Greenwood 1980). While dispersal potential is particularly high in the marine environment, many highly mobile marine species show significant degrees of population structuring. For example, resource specialization in North Atlantic killer whale populations corresponds with genetic differentiation in the absence of physical barriers to gene flow (Foote et al. 2011). In addition, a genetic study of highly migratory humpback whales in the North Pacific revealed low nuclear differentiation and higher structuring among feeding grounds with mitochondrial DNA (mtDNA) markers (Baker et al. 1998). 
The green turtle Chelonia mydas is another example of a highly migratory marine species with a complex life history. The green turtle is globally distributed in tropical and subtropical waters. Some threats to marine turtles include fisheries bycatch, over-harvest of eggs, meat or other turtle products, and coastal development (Wallace et al. 2011). Various life stages are spent in different oceanic habitats, and once sexually mature, individuals migrate extensively between foraging sites and rookeries (Meylan 1982, Carr 1986). While female green turtles are known to exhibit philopatry when nesting, there are limited data to suggest that males exhibit the same natal homing reproductive behavior (FitzSimmons et al. 1997a,b). Even if males return to natal regions to breed, they could still provide a means for gene flow among nesting populations if mating were occurring during migration or within mixed foraging aggregations (FitzSimmons et al. 1997b). To investigate the breeding strategy of males, nuclear (nDNA) markers can be used to assess the level of male-mediated gene flow and population subdivision. Due to the complex life history exhibited by C. mydas and the Endangered and Threatened IUCN status of all of its populations globally (excepting Hawaii), a clear understanding of population connectivity is critical for proper management strategies (Seminoff 2004, Wallace et al. 2011). Marine turtles have generally been listed globally under IUCN threats categories and the US Endangered Species Act, although there is a growing need to identify other smaller units to conserve below the species level that address regional and local patterns of diversity and adaptation. This requires the ability to assess whether populations are spatially and biologically distinct (Waples \& Gaggiotti 2006, Taylor et al. 2010, Wallace et al. 2011). Genetic information as a complement to monitoring and tagging can enhance our understanding of ecology and life history and ultimately aid in the definition of conservation units for a more comprehensive management strategy for green turtles.

Numerous methods have been used to detect movements and interactions among sea turtle populations. Tagging experiments have revealed strong nest site fidelity, in which females return faithfully to the same rookery to nest in consecutive breeding seasons (Carr 1967, Limpus et al. 1992, Encalada et al. 1996). In addition, the use of mtDNA markers has complemented tagging studies by confirming female philopatry and maternal population subdivision in green turtles (Meylan et al. 1990, Bowen et al. 1992, Norman et al. 1994, Dutton et al. 1996, Encalada et al.
1996, FitzSimmons et al. 1997a,b, Dethmers et al. 2006).

Bowen et al. (1992) conducted a study of mtDNA restriction site markers including samples representing 15 green turtle nesting locations from every major ocean basin inhabited by Chelonia mydas: Atlantic, Mediterranean, Indian, and Pacific. This analysis suggested limitations to female-mediated gene flow among rookery populations. Another study of mtDNA control region sequences among 27 green turtle rookeries in the Indo-Pacific Ocean region (Dethmers et al. 2006) revealed 25 distinct haplotypes, and subsequent analysis indicated 17 genetically distinct breeding stocks. While these studies provided useful information about the geographical scale of genetic exchange among rookeries, the results were confined to female lineages (mtDNA) and could not address unresolved questions concerning male-mediated gene flow or the mating system as a whole (Bowen et al. 1992, Karl et al. 1992).

Additional research included restriction fragment length polymorphism (RFLP) analysis of single-copy nuclear DNA (Karl et al. 1992), the sequencing of nuclear loci (Karl \& Bowen 1999), and investigation of the mitochondrial cytochrome $b$, ND4-leucine, and the control region containing the displacement loop (D loop) (Bowen et al. 1993, Dutton et al. 1996). These studies aimed to detect higher resolution of genetic variation among regional breeding populations of Chelonia mydas. The Karl et al. (1992) nuclear RFLP study revealed weak subdivision among proximate nesting populations, from which they inferred that a significant amount of male-mediated gene flow occurs between maternally isolated regional populations. With 4 microsatellite loci, Roberts et al. (2004) found a higher level of interoceanic versus intraoceanic population subdivision, which was principally in agreement with Karl et al. (1992) and Bowen et al. (1992), suggesting that intraoceanic populations are connected by gene flow principally through male dispersal. While informative, the lack of differentiation found in these earlier studies may have been due to the low number of nuclear microsatellite markers (Bernatchez \& Duchesne 2000).

In contrast, studies by FitzSimmons et al. $(1997 \mathrm{a}, \mathrm{b})$ using mtDNA control region sequences and microsatellites found evidence of significant genetic differences among Chelonia mydas rookeries located around the Australian coast. These studies, while on a smaller geographic scale, show genetic support for male philopatry and limited male-mediated gene flow between some C. mydas populations. While they provide useful information, the conclusions of 
recent nuclear DNA studies are only weakly supported given the small sample sizes and limited marker sets that have been used. This suggests the need for more extensive and statistically powerful genetic analysis of biparentally inherited nuclear markers among marine turtle populations to clarify the boundaries of genetically distinct populations and assess nuclear gene flow between maternally isolated rookeries (Dutton et al. 2013).

Single nucleotide polymorphisms (SNPs) show great promise as a common type of polymorphism in many genomes. An SNP is the result of a single nucleotide mutation event altering the sequence of a DNA molecule; they typically occur every 300 to 1000 bp in most genomes (Aitken et al. 2004). Green turtles were found to have 1 SNP every 75 screened nucleotides (Roden et al. 2009). The relatively high prevalence of SNPs compared with microsatellites creates the potential for the discovery and screening of high numbers of loci. In addition, SNPs show great promise as a nuclear marker to ultimately replace microsatellites, due to higher data quality and genotyping efficiency for population and evolutionary studies (Aitken et al. 2004, Morin et al. 2004, Morin \& McCarthy 2007).

SNP genotyping assays $(\mathrm{N}=29)$ developed and optimized by Roden et al. (2009) and microsatellites $(\mathrm{N}=10)$ characterized by Dutton \& Frey (2009) were used to test for population structure among 5 Pacific Chelonia mydas nesting populations throughout the

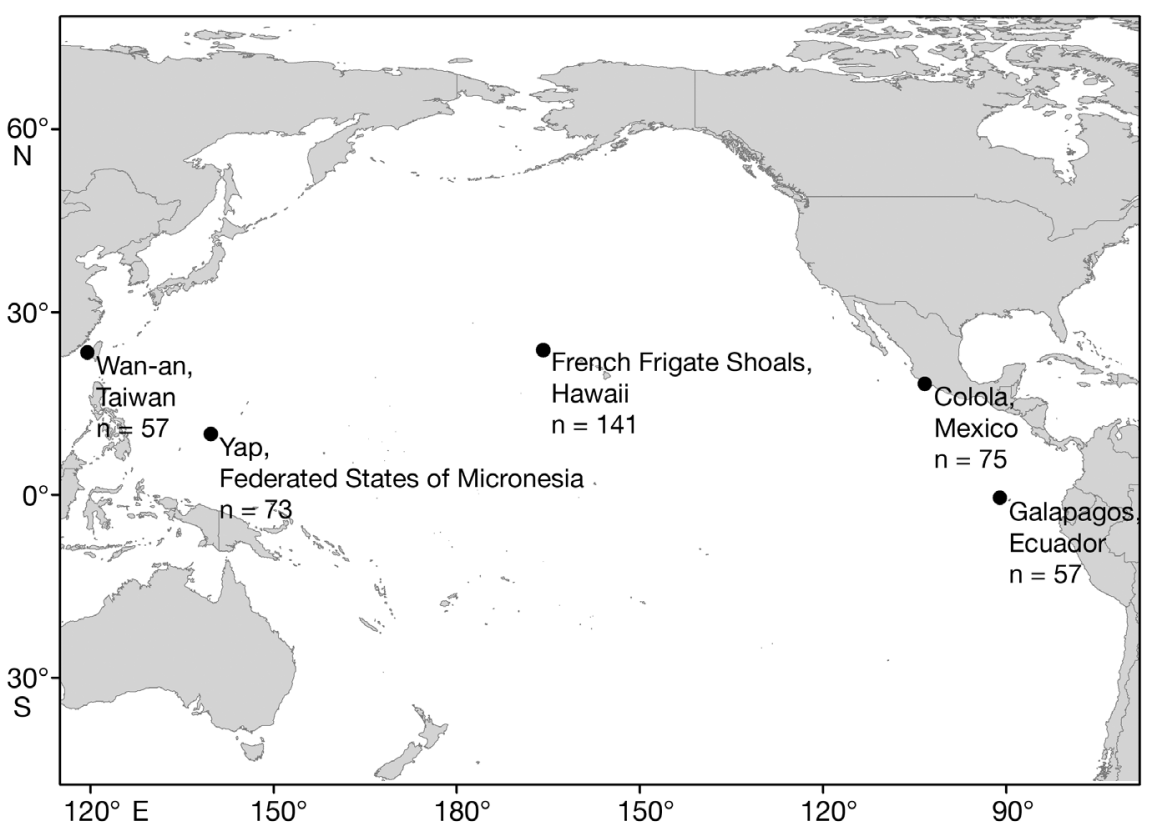

Fig. 1. Collection locations and sample sizes for nesting Chelonia mydas samples used in this study
Pacific Ocean. Our goal was to compare the level of differentiation and patterns of variation detected with these 2 classes of nuclear markers to build on previous mtDNA studies in order to obtain a more holistic understanding of gene flow and understand how males might be dispersing and contributing to the mating system among our sampled rookeries. Results of this study are particularly relevant to delineating the appropriate population units for conservation.

\section{MATERIALS AND METHODS}

\section{Sampled populations and DNA extraction}

A total of 403 genetic samples from nesting beaches in Colola, Mexico; French Frigate Shoals, Hawaii, USA; Galapagos Islands, Ecuador; Wan-an, Taiwan; and Yap, Federated States of Micronesia, were collected from 1995 to 2007 to represent eastern, central and western Pacific Chelonia mydas populations (Fig. 1). Blood and tissue samples were collected from nesting female green turtles by methods outlined in Dutton (1996). Upon collection, each individual's flipper tag or passive integrated transponder tag was recorded to avoid repeat sampling. Specimens included packed red blood cells that were frozen or stored in lysis buffer and small skin biopsies preserved in either $20 \%$ dimethyl sulphoxide solution saturated with sodium chloride or a saturated sodium chloride solution in distilled water (Dutton 1996). DNA was extracted from collected tissues using a variety of methods, including silica-based filter purification (Qiagen), standard phenol/chloroform extraction, and blood lysis buffer extraction (Grimberg et al. 1989).

\section{Genotyping and analysis}

All population samples were genotyped for 29 SNP loci as characterized in Roden et al. (2009). As a quality control measure, each genotyping assay run included at least 5 positive control samples of known genotype and 2 negative controls representing a multiplex blank and 
genotyping reaction blank. Error rates were calculated based on conflicting genotypes after duplicate genotyping. The per-allele error rate was calculated as the ratio of the differing replicated alleles to the total number of alleles (Morin et al. 2009). Samples with $>20 \%$ missing genotype data were removed from analysis.

In addition, genotype data were generated for the same sample set with 10 microsatellite loci previously found to be variable in green turtles (Dutton \& Frey 2009). Microsatellite markers included A6, B108, B116, C102, D1, D115, D2, and D108 (Dutton \& Frey 2009), along with D102 (F: TCA TGG ATC TTA AAA GCA CAG, R: TTT CTG GAC ATC AGG AGA GTA T) and D107 (F: CCT TTC ATC CTT CAG CAG T, R: GGC TTT GCC TTG TGT ATT T). PCR amplification, fragment separation, and size analysis were performed according to methods outlined in Dutton \& Frey (2009). To facilitate normalization of allele sizes, standard reference samples with known genotypes were included with each run.

Both SNP and microsatellite data sets were screened for excess homozygosity and genotypes that were highly influential on overall Hardy-Weinberg equilibrium (HWE) within each population with a jackknife analysis (Morin et al. 2009) and Bonferronicorrection for multiple comparisons. Influential individual genotypes were considered to be potential errors and regenotyped. After investigation, suspect genotype errors were either verified through replication or removed from further analysis due to ambiguous results.

All SNP and microsatellite loci were analyzed for linkage disequilibrium using Arlequin 3.1 (Excoffier et al. 2005). SNPs discovered within the same screening locus, and therefore known to be linked, were combined into haplotypes using the program PHASE v.2.1 (burn-in $=5000$, iterations $=10000$, thin $=10$, probability threshold $=0.5$ ) (Stephens et al. 2001, Stephens \& Donnelly 2003).

Several divergence metrics were calculated for each data set, in addition to both data sets combined. Calculations of the fixation index $\left(F_{\mathrm{ST}}\right)$ (Weir \& Cockerham 1984) and an unbiased analog of the fixation index $\left(G^{\prime \prime}{ }_{\text {ST }}\right)$ (Meirmans \& Hedrick 2011), were performed using custom scripts coded in $\mathrm{R}$ (v.2.1.3.0) (R Development Core Team 2011). For all analyses, 1000 permutations were used to calculate p-values. An unweighted pair group method with arithmetic mean (UPGMA) consensus tree of the combined SNP and microsatellite $F_{\mathrm{ST}}$ values was constructed using the program MEGA v.5.05 (Tamura et al. 2011).

\section{RESULTS}

\section{SNPs}

Genotypes were successfully generated for 353 individuals across 29 SNP loci. We removed 15 samples prior to analysis due to a genotyping success rate of $<80 \%$. Replicate analysis of the green turtle SNP data indicated a per-allele error rate of $0.5 \%$. No SNP locus pairs showed significant linkage across all 5 populations other than ones from loci known to be physically linked from our SNP discovery sequencing (Roden et al. 2009). Nine locus pairs known to be linked were combined into haplotypes using the program PHASE v.2.1 (Stephens et al. 2001, Stephens \& Donnelly 2003). Phased haplotypes were inferred according to known linkage associations as described in Roden et al. (2009), except that SSCM4 was not phased into a 3-SNP haplotype with SSCM10 and SSCM10b due to no evidence of significant linkage disequilibrium in these analyses. After phasing of linked SNPs, 20 loci (nine 2-SNP haplotypes and 11 independent SNP markers) were analyzed for population structure. Taiwan, Yap, and Galapagos nesting populations were in HWE across all SNP loci. The Hawaiian and Mexican populations each had 1 phased marker out of HWE (SSCM10_SSCM10b and SSCM22b, respectively). Population pairwise $F_{\mathrm{ST}}$ and $G$ "ST comparisons showed statistically significant differences across all populations ( $\mathrm{p} \leq 0.001$; Table 1).

\section{Microsatellites}

Genotypes were generated for 308 individuals across 10 microsatellite loci. Two loci, D108 and B116, each deviated significantly from HWE in at least 4 out of the 5 analyzed populations and were removed from further analysis. In addition, locus D1 was significantly out of HWE in 2 of the 5 study populations; however, it was not omitted from further analysis as it was not significant enough to show up in all populations. None of the microsatellite locus pairs analyzed showed significant linkage $(p<0.05)$ across all 5 populations, though 6 locus pairs were significant across 2 populations. Population pairwise $F_{\mathrm{ST}}$ and $G^{\prime \prime}$ ST comparisons with 8 microsatellite loci indicated statistically significant differences across all populations ( $\leq 0.001$; Table 1$). F_{\text {ST }}$ and $G{ }^{\prime \prime}$ Sт population pairwise differences were also calculated without locus D1 in the data set, and all population comparisons remained significantly different (data not shown). 
Table 1. Population structure results for pairwise analyses. Statistically significant results $(\mathrm{p}<0.001)$ are shown in bold. Population sample sizes $(\mathrm{n} / \mathrm{n})$ are shown as a pairwise comparison. SNP: single nucleotide polymorphism; $F_{\mathrm{ST}}$ : fixation index; $G^{\prime \prime}$ ST: unbiased analog of the fixation index

\begin{tabular}{|c|c|c|c|c|c|c|c|c|c|}
\hline \multirow[t]{2}{*}{ Pairwise comparison } & \multicolumn{3}{|c|}{ SNPs } & \multicolumn{3}{|c|}{ - Microsatellites -} & \multicolumn{3}{|c|}{ - SNPs/microsatellites } \\
\hline & $\mathrm{n}$ & $F_{\mathrm{ST}}$ & $G_{\mathrm{ST}}$ & $\mathrm{n}$ & $F_{\mathrm{ST}}$ & $G_{\mathrm{ST}}^{\prime \prime}$ & $\mathrm{n}$ & $F_{\mathrm{ST}}$ & $G^{\prime \prime} \mathrm{ST}$ \\
\hline Galapagos vs. Hawaii & $57 / 128$ & 0.110 & 0.160 & $54 / 90$ & 0.066 & 0.231 & $57 / 138$ & 0.090 & 0.154 \\
\hline Galapagos vs. Mexico & $57 / 64$ & 0.020 & 0.019 & $54 / 55$ & 0.008 & -0.007 & $57 / 70$ & 0.012 & 0.007 \\
\hline Galapagos vs. Taiwan & $57 / 33$ & 0.145 & 0.207 & $54 / 40$ & 0.099 & 0.358 & $57 / 40$ & 0.124 & 0.216 \\
\hline Galapagos vs. Yap & $57 / 71$ & 0.144 & 0.210 & $54 / 69$ & 0.120 & 0.461 & $57 / 73$ & 0.132 & 0.234 \\
\hline Hawaii vs. Mexico & $128 / 64$ & 0.105 & 0.151 & $90 / 55$ & 0.070 & 0.237 & $138 / 70$ & 0.088 & 0.150 \\
\hline Hawaii vs. Taiwan & $128 / 33$ & 0.107 & 0.150 & $90 / 40$ & 0.112 & 0.380 & $138 / 40$ & 0.110 & 0.187 \\
\hline Hawaii vs. Yap & $128 / 71$ & 0.125 & 0.186 & $90 / 69$ & 0.119 & 0.427 & $138 / 73$ & 0.122 & 0.218 \\
\hline Mexico vs. Taiwan & $64 / 33$ & 0.163 & 0.227 & $55 / 40$ & 0.100 & 0.342 & $70 / 40$ & 0.123 & 0.210 \\
\hline Mexico vs. Yap & $64 / 71$ & 0.167 & 0.242 & $55 / 69$ & 0.131 & 0.485 & $70 / 73$ & 0.140 & 0.248 \\
\hline Taiwan vs. Yap & $33 / 71$ & 0.020 & 0.015 & $40 / 69$ & 0.109 & 0.383 & $40 / 73$ & 0.060 & 0.098 \\
\hline
\end{tabular}

The combined SNP and microsatellite results revealed a similar pattern of significance and structure seen with either data set alone. The highest degree of structure was found between Mexico and Yap $\left(G{ }^{\prime \prime}{ }_{\text {ST }}=\right.$ 0.248 ), while the weakest structure was found when comparing Galapagos and Mexico $\left(G{ }^{\prime \prime}{ }_{\text {ST }}=0.007\right.$; Table 1). A UPGMA consensus tree of genetic relationships based on combined $F_{\mathrm{ST}}$ values revealed 3 distinct clusters; the first included Galapagos and Mexico, the second clustered those 2 with Hawaii, and the third included Taiwan and Yap (Fig. 2).

\section{DISCUSSION}

The statistically significant differences found between the population pairs in the Pacific sample set for both SNPs and microsatellites provide genetic evidence of limited male- and female-mediated gene flow. These findings advance previous research on population connectivity and male green turtle behavior and provide evidence of male philopatry, documented previously only through genetic testing of Chelonia mydas along the Australian coast (FitzSimmons et al. 1997a,b). The existence of male-mediated gene flow has been assumed for green turtle popula-

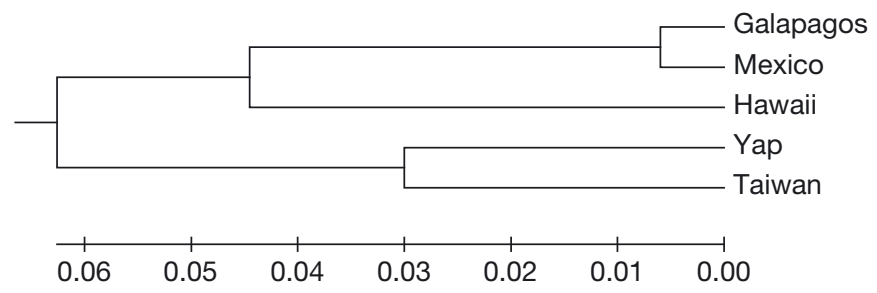

Fig. 2. UPGMA tree of combined microsatellite and single nucleotide polymorphism fixation index ( $F_{\mathrm{ST}}$ scale bar) values between surveyed green turtle rookery pairs in the Pacific tions in past studies as an explanation for low genetic structuring found with nuclear markers (Roberts et al. 2004). Our results contrast with those of previous nuclear studies that did not find significant population subdivision among maternally distinct populations within the Pacific based on 4 microsatellite loci (Roberts et al. 2004). The structure we detected with SNPs and microsatellites is undoubtedly a result of increased statistical power of the tests due to the use of higher numbers of markers and larger sample sizes than the previous studies. These data revaluate the use of nuclear markers in green turtle population dynamics. While significantly different, the populations tested represent a broad geographical range, and further work is needed to examine structuring on a finer scale, particularly among the numerous nesting populations scattered throughout the western Pacific (Dethmers et al. 2006).

Meirmans \& Hedrick's (2011) $G^{\prime \prime}$ ST was used as an $F_{\mathrm{ST}}$ analog due to concerns over the limitations of F-statistics with highly variable loci, especially when markers with different mutation rates or differing levels of heterozygosity are compared. By including $G^{\prime \prime}{ }_{\mathrm{ST}}$, it was possible to examine the impact of the number of alleles, mutation rate, and heterozygosity levels on estimates of population differentiation. $G^{\prime \prime}$ ST is less affected by heterozygosity and therefore can be used as a more appropriate measure to compare results from markers with different numbers of alleles, such as SNPs and microsatellites. Therefore, based on Meirmans \& Hedrick (2011), $F_{\mathrm{ST}}$ is an appropriate measure of differentiation with no standardization necessary for SNP data, while $G{ }^{\prime \prime}{ }_{\text {ST }}$ may be more suited to the multi-allelic microsatellite results. As expected, $G_{\text {ST }}^{\prime \prime}$ values here were similar to $F_{\mathrm{ST}}$ values for SNPs but substantially elevated for microsatellites (Table 1). 
These data are consistent with results of mtDNA studies that indicate similar regional structuring among Pacific Chelonia mydas nesting populations (Dethmers et al. 2006). The $F_{\mathrm{ST}}$ and $G^{\prime \prime}$ ST results from our SNP data indicated that the lowest level of population differentiation was found between the geographically proximate eastern Pacific populations Mexico and Galapagos, as well as between the western Pacific populations Taiwan and Yap. Our microsatellite data $F_{\mathrm{ST}}$ and $G^{\prime \prime}$ ST results were able to detect greater population subdivision between Taiwan and YAP when compared with SNPs, but the level of substructuring, while significant, was not as pronounced between the Galapagos and Mexico rookeries. These results therefore suggest a greater extent of connectivity between the latter 2 populations relative to the others, possibly due to geographical proximity or shared migration and foraging sites. An additional factor to be considered is that the greater genetic connectivity among the regional rookeries may indicate recent shared ancestry and therefore evolutionary connectivity as opposed to ongoing gene flow (Bowen et al. 1992). Pairwise $F_{\mathrm{ST}}$ values from mtDNA (and therefore maternal lineage) haplotype frequencies published for the same rookeries used in our study indicate similar patterns, with greater connectivity between Galapagos and Mexico $\left(F_{\mathrm{ST}}=0.21\right)$ relative to the other central and western Pacific rookeries $\left(F_{\mathrm{ST}}=0.44-0.99\right)$ (Dethmers et al. 2006, Cheng et al. 2008, Dutton et al. 2008), which likely reflect the more recent colonization by green turtles in the eastern Pacific. Furthermore, simulation studies have shown that $F_{\mathrm{ST}}$ values can be substantially higher in mtDNA when compared with nDNA between populations that have recently diverged, before eventually converging at equilibrium (Karl et al. 2012). The relatively low level of detectable nuclear differentiation may not reflect the higher discreteness detected by mtDNA analysis if isolation (through colonization) has occurred relatively recently and the populations are not yet in equilibrium.

This is the first study to examine population structure in a marine turtle species using SNPs. In addition, this study compares population subdivision between 2 different molecular marker types. Our results show that SNPs are as effective as microsatellites at detecting statistically significant differences among distant nesting populations and are consistent with general speculation that approximately 3 times as many SNPs would be needed in comparison to microsatellites to estimate population genetic parameters with statistical confidence (Brumfield et al. 2003). Moreover, SNPs offer additional benefits over microsatellite genotyping that include more costeffective genotyping methods, the ability for data to be easily shared and replicated across laboratories over time, and the capability to genotype poor-quality and historical samples. In addition, SNP data can be interpreted in a more straightforward manner in population genetic studies due to their simple mutation models and low levels of heterozygosity. We propose that SNP genotyping offers an efficient and useful method to address questions about the population structure of marine turtles as a complement to or replacement of existing microsatellite studies of this species.

\section{Conservation implications}

Sea turtles have complex life histories where adults breed at rookeries and migrate to foraging grounds that are usually shared with animals from multiple genetic stocks (Lahanas et al. 1998, Dutton et al. 2008). A recent comprehensive study based on mtDNA analysis of green turtles found that the foraging populations around the Hawaiian Archipelago all comprised 1 genetic stock that belonged to the single Hawaiian breeding population at French Frigate Shoals (Dutton et al. 2008). Our microsatellite and SNP results are consistent with the reported mtDNA findings and reinforce the view that Hawaiian green turtles represent a central North Pacific genetic management unit that is biologically and spatially distinct from other management units in the Pacific. In the eastern tropical Pacific, however, satellite, tagging and genetic studies suggest mixing of animals from different nesting populations at foraging grounds (Green 1984, Amorocho et al. 2012). Post-nesting migration of female green turtles from the Galapagos Islands included north-bound migration to Central America, residency in the Galapagos, and dispersal to oceanic waters southwest of Galapagos, illustrating the variability of migratory strategies to different foraging habitats within a single breeding population (Seminoff et al. 2008). Although breeding is generally believed to occur adjacent to the nesting beaches when females are reproductively receptive, the overlapping foraging areas perhaps offer greater opportunity for a low level of male-mediated gene flow between Galapagos and Mexico than between Hawaii and the eastern Pacific rookeries, and should not be ruled out as a potential factor contributing to the lower differentiation.

This study clearly demonstrates that on a broad regional scale, green turtle nesting populations in the 
western, central, and eastern Pacific are well-differentiated stocks that need to be managed accordingly. Our results suggest a stronger sub-division among regional stocks, improving our understanding over earlier studies, and confirm the model of gene flow proposed by Dutton et al. (2008) based on mtDNA, which indicates that green turtles in the Hawaiian Archipelago comprise a single distinct Pacific stock. Furthermore, understanding the links between foraging areas and breeding sites from which animals originate is of great importance to developing holistic conservation strategies for this trans-boundary species through genetic studies (Amorocho et al. 2012). Characterizing the genetic signatures of rookeries with an array of informative nuclear markers will improve capacity for stock assignments of turtles in mixed foraging aggregations, or those caught incidentally in fisheries, to better assess the impacts of threats to specific populations (Stewart et al. 2013). Future study to include additional key Pacific rookeries will provide a greater understanding of the connectivity between nesting and foraging aggregations and define stock boundaries to properly implement policy planning at the regional, national, and international levels (Wallace et al. 2011).

Acknowledgements. Laboratory analysis was funded by NMFS, Southwest Fisheries Science Center. We are grateful to Eric Archer for assistance with data analysis scripts and statistical analysis, along with Michael Jensen and Rich Cosgrove for help with figures. We also thank Lauren Hansen, Amanda Bowman, Carrie LeDuc, Robin LeRoux, Brittany Hanser, Vicki Pease, Amy Jue, and Erin LaCasella for laboratory assistance and support. We also thank Omar ChassinNoria, Jennifer Cruce, and Karen Frutchey for coordinating sample collection. Samples were collected under the respective national authorizations and CITES permit conditions as follows: samples from the Hawaiian Islands National Wildlife Refuge overseen by the USFWS, Department of the Interior; from the Galapagos National Park cooperation from the Charles Darwin Research Foundation; from Mexico with assistance from Omar Chassin-Noria, and permission from SEMARNAT. The manuscript was greatly improved by constructive review by Kelly Stewart and William Perrin.

\section{LITERATURE CITED}

Aitken N, Smith S, Schwarz C, Morin PA (2004) Single nucleotide polymorphism (SNP) discovery in mammals: a targeted-gene approach. Mol Ecol 13:1423-1431

> Amorocho DF, Abreu-Grobois FA, Dutton PH, Reina RD (2012) Multiple distant origins for green sea turtles aggregating off Gorgona Island in the Colombian Eastern Pacific. PLoS ONE 7:e31486

> Baker CS, Medrano-Gonzalez L, Calambokidis J, Perry A and others (1998) Population structure of nuclear and mitochondrial DNA variation among humpback whales in the North Pacific. Mol Ecol 7:695-707

Bernatchez L, Duchesne P (2000) Individual-based genotype analysis in studies of parentage and population assignment: how many loci, how many alleles? Can J Fish Aquat Sci 57:1-12

Bowen BW, Meylan AB, Ross JP, Limpus CJ, Balazs GH, Avise JC (1992) Global population structure and natural history of the green turtle Chelonia mydas in terms of matriarchal phylogeny. Evolution 46:865-881

Bowen BW, Nelson WS, Avise JC (1993) A molecular phylogeny for marine turtles: trait mapping, rate assessment, and conservation relevance. Proc Natl Acad Sci USA 90: 5574-5577

> Brumfield RT, Beerli P, Nickerson DA, Edwards SV (2003) The utility of single nucleotide polymorphisms in inferences of population history. Trends Ecol Evol 18:249-256

Carr AF (1967) So excellent a fishe: a natural history of sea turtles. Scribner, New York, NY

Carr A (1986) Rips, FADS and little loggerheads. Bioscience 36:92-100

> Cheng IJ, Dutton PH, Chen CL, Chen HC, Chen YH, Shea JW (2008) Comparison of the genetics and nesting ecology of two green turtle rookeries. J Zool 276:375-384

$>$ Dethmers KE, Broderick D, Moritz C, Fitzsimmons NN and others (2006) The genetic structure of Australasian green turtles (Chelonia mydas): exploring the geographical scale of genetic exchange. Mol Ecol 15:3931-3946

Dutton PH (1996) Methods for collection and preservation of samples for sea turtle genetic studies. Proc Int Symp Sea Turtle Conserv Genet. NOAA Tech Memo NMFSSEFSC-396:171

> Dutton PH, Frey A (2009) Characterization of polymorphic microsatellite markers for the green turtle (Chelonia mydas). Mol Ecol Resour 9:354-356

> Dutton PH, Davis SK, Guerra T, Owens D (1996) Molecular phylogeny for marine turtles based on sequences of the ND4-leucine tRNA and control regions of mitochondrial DNA. Mol Phylogenet Evol 5:511-521

> Dutton PH, Balazs GH, LeRoux RA, Murakawa SKK, Zarate P, Martínez LS (2008) Composition of Hawaiian green turtle foraging aggregations: mtDNA evidence for a distinct regional population. Endang Species Res 5:37-44

Dutton PH, Roden SE, Stewart KR, LaCasella E and others (2013) Population stock structure of leatherback turtles (Dermochelys coriacea) in the Atlantic revealed using mtDNA and microsatellite markers. Conserv Genet 14: 625-636

Encalada SE, Lahanas PN, Bjorndal KA, Bolten AB, Miyamoto MM, Bowen BW (1996) Phylogeography and population structure of the Atlantic and Mediterranean green turtle Chelonia mydas: a mitochondrial DNA control region sequence assessment. Mol Ecol 5:473-483

Excoffier L, Laval G, Schneider S (2005) Arelquin ver. 3.0: an integrated software package for populations genetics data analysis. Evol Bioinform Online 1:47-50

FitzSimmons NN, Limpus CJ, Norman JA, Goldizen AR, Miller JD, Moritz C (1997a) Philopatry of male marine turtles inferred from mitochondrial DNA markers. Proc Natl Acad Sci USA 94:8912-8917

> FitzSimmons NN, Moritz C, Limpus CJ, Pope L, Prince R (1997b) Geographic structure of mitochondrial and nuclear gene polymorphisms in Australian green turtle populations and male-biased gene flow. Genetics 147: 1843-1854 
Foote AD, Vilstrup JT, De Stephanis R, Verborgh P and others (2011) Genetic differentiation among North Atlantic killer whale populations. Mol Ecol 20:629-641

Green DJ (1984) Long-distance movements of Galapagos green turtles. J Herpetol 18:121-130

Greenwood PJ (1980) Mating systems, philopatry and dispersal in birds and mammals. Anim Behav 28:1140-1162

Grimberg J, Nawoschik S, Belluscio L, McKee R, Turck A, Eisenberg A (1989) A simple and efficient non-organic procedure for the isolation of genomic DNA from blood. Nucleic Acids Res 17:8390

Karl SA, Bowen BW (1999) Evolutionary significant units versus geopolitical taxonomy: Molecular systematics of an endangered sea turtle (genus Chelonia). Conserv Biol 13:990-999

Karl SA, Bowen BW, Avise JC (1992) Global population genetic structure and male-mediated gene flow in the green turtle Chelonia mydas RFLP analyses of anonymous nuclear loci. Genetics 131:163-173

Karl SA, Toonen RJ, Grant WS, Bowen BW (2012) Common misconceptions in molecular ecology: echoes of the modern synthesis. Mol Ecol 21:4171-4189

Lahanas PN, Bjorndal KA, Bolten AB, Encalada SE, Miyamoto MM, Valverde RA, Bowen BW (1998) Genetic composition of a green turtle (Chelonia mydas) feeding ground population: evidence for multiple origins. Mar Biol 130:345-352

Limpus CJ, Miller JD, Parmenter CJ, Reimer D, McLachlan N, Webb R (1992) Migration of green (Chelonia mydas) and loggerhead (Caretta caretta) turtles to and from eastern Australian rookeries. Wildl Res 19:347-358

Meirmans PG, Hedrick PW (2011) Assessing population structure: $F_{\mathrm{ST}}$ and related measures. Mol Ecol Resour 11: 5-18

Meylan AB (1982) Sea turtle migration: evidence from tag returns. In: Bjorndal KA (ed) Biology and conservation of sea turtles. Smithsonian Institution Press, Washington, DC, p 91-100

Meylan AB, Bowen BW, Avise JC (1990) A genetic test of the natal homing versus social facilitation models for green turtle migration. Science 248:724-727

Morin PA, McCarthy M (2007) Highly accurate SNP genotyping from historical and low-quality samples. Mol Ecol Notes 7:937-946

Morin PA, Luikart G, Wayne RK, SNP Workshop Group (2004) SNPs in ecology, evolution and conservation. Trends Ecol Evol 19:208-216

Morin PA, Leduc RG, Archer FI, Martien KK, Huebinger R, Bickham JW, Taylor BL (2009) Significant deviations from Hardy-Weinberg equilibrium caused by low levels of microsatellite genotyping errors. Mol Ecol Resour 9: 498-504

> Norman JA, Moritz C, Limpus CJ (1994) Mitochondrial DNA

Editorial responsibility: Paolo Casale,

Rome, Italy control region polymorphisms: genetic markers for ecological studies of marine turtles. Mol Ecol 3:363-373

R Development Core Team (2011) R: A language and environment for statistical computing. R Foundation for Statistical Computing, Vienna

Roberts MA, Schwartz TS, Karl SA (2004) Global population genetic structure and male-mediated gene flow in the green sea turtle (Chelonia mydas): analysis of microsatellite loci. Genetics 166:1857-1870

$>$ Roden SE, Dutton PH, Morin PA (2009) Characterization of single nucleotide polymorphism markers for the green sea turtle (Chelonia mydas). Mol Ecol Resour 9: 1055-1060

Seminoff JA (2004) Chelonia mydas. In: IUCN 2011. IUCN Red List of Threatened Species. Version 2011.1. Available at www.iucnredlist.org

Seminoff JA, Zárate P, Coyne M, Foley DG, Parker D, Lyon BN, Dutton PH (2008) Post-nesting migrations of Galápagos green turtles Chelonia mydas in relation to oceanographic conditions: integrating satellite telemetry with remotely sensed ocean data. Endang Species Res 4: $57-72$

Stephens M, Donnelly P (2003) A comparison of Bayesian methods for haplotype reconstruction from population genotype data. Am J Hum Genet 73:1162-1169

Stephens M, Smith NJ, Donnelly P (2001) A new statistical method for haplotype reconstruction from population data. Am J Hum Genet 68:978-989

Stewart KR, James MC, Roden SE, Dutton PH (2013) Assignment tests, telemetry and tag-recapture data converge to identify natal origins of leatherback turtles foraging in Atlantic Canadian waters. J Anim Ecol, doi:10.1111/ 1365-2656.12056

- Tamura K, Peterson D, Peterson N, Stecher G, Nei M, Kumar S (2011) MEGA5: molecular evolutionary genetics analysis using maximum likelihood, evolutionary distance, and maximum parsimony methods. Mol Biol Evol 28: 2731-2739

Taylor B, Martien K, Morin P (2010) Identifying units to conserve using genetic data. In: Boyd IL, Bowen WD, Iverson SJ (eds) Marine mammal ecology and conservation: a handbook of techniques. Oxford University Press, Oxford, p 306-324

Wallace BP, DiMatteo AD, Bolten AB, Chaloupka MY and others (2011) Global conservation priorities for marine turtles. PLoS ONE 6:e24510

- Waples RS, Gaggiotti O (2006) What is a population? An empirical evaluation of some genetic methods for identifying the number of gene pools and their degree of connectivity. Mol Ecol 15:1419-1439

> Weir BS, Cockerham CC (1984) Estimating F-statistics for the analysis of population-structure. Evolution 38: 1358-1370

Submitted: October 11, 2012; Accepted: January 31, 2013 Proofs received from author(s): May 13, 2013 